九州大学学術情報リポジトリ

Kyushu University Institutional Repository

\title{
Is pH of Greenhouse Soils Measured Adequately?
}

Than, Aye Aye

Laboratory of Soils, Division of Soil Science and Plant Production, Department of Plant

Resources, Graduate School of Bioresources and Bioenvironmental Sciences, Kyushu University

Shoji, Kazuyuki

Laboratory of Soils, Division of Soil Science and Plant Production, Department of Plant

Resources, Graduate School of Bioresources and Bioenvironmental Sciences, Kyushu University

Mori, Yuki

Laboratory of Soils, Division of Soil Science and Plant Production, Department of Plant Resources, Faculty of Agriculture, Kyushu University

Fujitomi, Shin-Ichi

Fukuoka Agricultural Experimental Station

他

https://doi.org/10.5109/16137

出版情報: 九州大学大学院農学研究院紀要. 54 (2)，pp.499-503，2009-10-29. Faculty of Agriculture, Kyushu University

バージョン :

権利関係: 


\title{
Is pH of Greenhouse Soils Measured Adequately?
}

\author{
Aye Aye THAN ${ }^{1 *}$, Kazuyuki SHOJI ${ }^{1}$, Yuki MORI ${ }^{2}$, Shin-Ichi FUJITOMI ${ }^{3}$ \\ and Shin-Ichiro WADA ${ }^{2}$
}

\author{
Laboratory of Soils, Division of Soil Science and Plant Production, Department of Plant Resources, \\ Faculty of Agriculture, Kyushu University, Fukuoka 812-8581, Japan \\ (Received June 29, 2009 and accepted July 13, 2009)
}

\begin{abstract}
We measured the soil pH on fourteen soil samples collected from greenhouses under intensive fertilizer application. All the soil samples contained carbonate, but the $\mathrm{pH}$ values measured by conventional method were too low in view of carbonate equilibrium. We examined the effect of the soil to water ratio, shaking time and standing time and found that the $\mathrm{pH}$ gradually increased as the standing time was prolonged. It reached a maximum after 192 to $264 \mathrm{~h}$ of standing and then decreased. The maximum $\mathrm{pH}$ values were fairly close to those that are calculated from the thermodynamic equation based on carbonate equilibrium.
\end{abstract}

\section{INTRODUCTION}

It is a common understanding that the soil $\mathrm{pH}$ is the single most informative quantity that characterizes nature of soils. Soil pH reflect the exchangeable cation composition of soils, controls the mobility of trace elements in soils and greatly affect the microbial and enzymatic activity in soils. From physico-chemical standpoint, the $\mathrm{pH}$ of interstitial solution, i. e., soil solution, would be the natural quantity to be measured to get insight into those soil processes. However, sampling soil solution is extremely laborious and time consuming and it is not adequate for the method of routine soil testing. In routine practices, the $\mathrm{pH}$ of soil suspension at soil to water ratios (SWR) ranging from 1:1 (Thomas, 1996) to 1:5 (Committee on Soil Testing, 2000; ISO, 2005) is measured and designated as soil $\mathrm{pH}$.

The typical water content of field-moist upland soils is around 0.15 to $0.25 \mathrm{~kg} \mathrm{~kg}^{-1}$ and making a suspension from a soil sample inevitably dilute the soil solution retained in its interstices and, in turn, may alter the $\mathrm{pH}$. However the effect of dilution is not as straightforward as might be expected. Davis (1943) showed that the change in soil $\mathrm{pH}$ associated with 10-fold dilution was not more than 0.4 unit. Committee on Soil Testing (2000) examined the effect of dilution on the measured $\mathrm{pH}$ for some soils and clay minerals and reported that the SWR did not affect the $\mathrm{pH}$ significantly in a SWR range from 1:1 to 1:10. Okajima (1981) measured both the soil $\mathrm{pH}$ and soil solution $\mathrm{pH}$ on several tens of soil samples and found that the difference between the two pHs was mostly less than 0.5 unit. Thus, there is a consensus that the SWR does not significantly affect the measured soil $\mathrm{pH}$ and ISO (2005) adopted taking a soil sample with a measuring

\footnotetext{
1 Laboratory of Soils, Division of Soil Science and Plant Production, Department of Plant Resources, Graduate School of Bioresources and Bioenvironmental Sciences, Kyushu University

2 Laboratory of Soils, Division of Soil Science and Plant Production, Department of Plant Resources, Faculty of Agriculture, Kyushu University

Fukuoka Agricultural Experimental Station

* Corresponding author (E-mail: aye2than2006@yahoo.com)
}

spoon accommodating approximately $5 \mathrm{~mL}$ instead of weighing.

In contrast to the effect of SWR, there seems to be some disagreement with regard to the time required for equilibration. The Soil Science Society of America recommends 10 min after mixing soil and deionized water at a SWR of 1:1 (Thomas, 1996). Japanese Society of Soil Science and Plant Nutrition, on the other hand, advocated that the standing time should be more than $1 \mathrm{~h}$ at a SWR of 1:2.5 (Soil Environmental Analysis Methods Committee, 1997). Japanese Geotechnical Society and ISO adopted in their standards the SWR of approximately 1:5 and the standing times not more than $3 \mathrm{~h}$ (Committee on Soil Testing, 2000; ISO, 2005). According to these de facto standards, the time for equilibration should be longer than 10 min but no longer than $3 \mathrm{~h}$.

Recently we carried out a series of soil testing on several tens of soil sample collected in greenhouses in Fukuoka prefecture, Japan and found that the prescribed methods for $\mathrm{pH}$ measurement are not suitable for equilibrium-pH measurement. All the soil samples contained small amount of free carbonate. Nevertheless, the measured $\mathrm{pH}$ values were significantly lower than the values anticipated for calcareous soils. The objective of the present study was to re-examine the effect of standing time on the soil $\mathrm{pH}$ determined on soil suspensions.

\section{MATERIALS AND METHODS}

\section{Soil samples}

Fourteen samples were collected from the Ap horizon of soils in greenhouses in Fukuoka prefecture. The greenhouses were being used for growing tomato, leek, spinach and komatsuna. The collected samples were airdried and passed through 2-mm screen and stored in plastic bags. As reference soil samples, Ap soil samples from an acidic soil collected in Korea was used.

\section{Experimental methods}

Basic chemical properties of the soil samples including $\mathrm{pH}$, organic carbon content and exchangeable cation composition were determined by the standard methods (Soil Environmental Analysis Methods Committee, 1977). 
The soil pH was measured at a SWR of 2.5. Carbonate content of the soil samples were determined by the procedure proposed by Wada (1997). Water soluble cations and anions were extracted by shaking with distilled water at a SWR of 1:5 for $24 \mathrm{~h}$. The cations and anions were determined by atomic absorption spectroscopy and ion chromatography.

In the $\mathrm{pH}$ measurement, $5.00 \mathrm{~g}$ soil samples were taken in plastic centrifuge tubes, mixed with deionized water at SWR of either 1:1, 1:2.5 or 1:5, shaken on a reciprocal shaker for either $15 \mathrm{~min}$., $30 \mathrm{~min}$ or $60 \mathrm{~min}$ and allowed to stand for up to $700 \mathrm{~h}$. The tubes were uncapped to keep the suspensions oxidative. In cases when the amount of soil available for $\mathrm{pH}$ measurement was limited, soil suspensions were prepared in reduced size keeping the SWR. A preliminary experiment showed that the reduced sample size did not affect the $\mathrm{pH}$ value even when only $1 \mathrm{~g}$ soil was used for preparing suspension. The $\mathrm{pH}$ was measured by immersing a glass electrode in supernatant of the soil-water mixtures. An F-24 pH meter combined with Type 6378 glass electrode (HORIBA Co., Kyoto) was used throughout the experiment. Sample preparation and $\mathrm{pH}$ measurement were carried out in a room kept at $25^{\circ} \mathrm{C}$.

The atmospheric $\mathrm{CO}_{2}$ concentration in the room where $\mathrm{pH}$ measurement was carried out was monitored by $\mathrm{CO}_{2}$ detector tube.

\section{RESULTS AND DISCUSSION}

The basic chemical properties of the soil samples are summarized in Table 1. As shown in the last column of the table, the F104, F206, F214 and F215 samples contained more than $10 \mathrm{cmol} \mathrm{kg}^{-1}$ of carbonate. Since the $\mathrm{CO}_{2}$ evolution during the carbonate determination almost completed in $5 \mathrm{~min}$, the carbonate is considered to be mostly calcite. Contrast to the soils from greenhouses, the soils used for comparison were acidic and Al dominated among the exchangeable cations.

Major cation and anion concentrations in the extract obtained at a SWR of 1:5 after $24 \mathrm{~h}$ shaking are listed in Table 2. Some soils contain large amount of soluble salts reflecting intensive fertilizer application. The comparison of Table 1 and Table 2 indicate that there is no clear

Table 1. Basic chemical properties of soil samples used

\begin{tabular}{|c|c|c|c|c|c|c|c|c|}
\hline \multirow{2}{*}{ Soil } & \multirow{2}{*}{$\mathrm{OC}^{*}$} & \multirow{2}{*}{$\mathrm{pH}$} & \multicolumn{5}{|c|}{ Exchangeable cation } & \multirow{2}{*}{ Carbonate } \\
\hline & & & $\mathrm{Ca}$ & $\mathrm{Mg}$ & $\mathrm{K}$ & $\mathrm{Na}$ & $\mathrm{Al}$ & \\
\hline & $\%$ & & \multicolumn{5}{|c|}{$-----------\mathrm{cmol}_{\mathrm{c}} \mathrm{kg}^{-1}-----------$} & $\mathrm{cmol} \mathrm{kg}^{-1}$ \\
\hline F104 & 3.08 & 7.0 & 30.6 & 4.3 & 1.8 & 0.6 & 0 & 30.8 \\
\hline F206 & 3.22 & 6.6 & 11.4 & 3.7 & 3.2 & 1.5 & 0 & 36.7 \\
\hline F215 & 3.94 & 6.6 & 28.0 & 10.1 & 0.5 & 0.5 & 0 & 22.4 \\
\hline $\mathrm{F} 214$ & 4.85 & 6.3 & 29.5 & 5.2 & 2.9 & 0.7 & 0 & 12.0 \\
\hline F151 & 1.88 & 5.6 & 19.2 & 5.6 & 0.3 & 0.4 & 0 & 7.6 \\
\hline F212 & 3.41 & 6.2 & 27.2 & 7.3 & 0.7 & 0.6 & 0 & 7.8 \\
\hline F324 & 2.60 & 7.0 & 21.6 & 2.7 & 1.7 & 0.3 & 0 & 4.8 \\
\hline F207 & 3.86 & 5.8 & 13.2 & 4.3 & 3.1 & 1.3 & 0 & 3.0 \\
\hline F213 & 2.81 & 6.5 & 21.0 & 4.5 & 1.5 & 1.0 & 0 & 2.8 \\
\hline F109 & 1.43 & 6.0 & 14.2 & 4.1 & 1.7 & 1.4 & 0 & 2.4 \\
\hline F211 & 3.28 & 6.5 & 17.4 & 3.2 & 1.1 & 0.7 & 0 & 1.0 \\
\hline F219 & 1.97 & 5.6 & 13.2 & 3.8 & 2.7 & 0.2 & 0 & 0.8 \\
\hline F323 & 3.80 & 6.3 & 12.8 & 3.0 & 1.3 & 0.2 & 0 & 0.8 \\
\hline F401 & 3.20 & 6.7 & 20.7 & 6.0 & 1.9 & 0.5 & 0 & 0.5 \\
\hline K1 & 1.58 & 4.5 & 1.5 & 0.6 & 0.2 & 0.1 & 3.2 & 0 \\
\hline
\end{tabular}

* organic carbon content

Table 2. Major ion concentrations in 1:5 water extracts

\begin{tabular}{llllllll}
\hline & $\mathrm{Ca}$ & $\mathrm{Mg}$ & $\mathrm{K}$ & $\mathrm{Na}$ & $\mathrm{Cl}$ & $\mathrm{SO} 4$ & $\mathrm{NO}_{3}$ \\
\hline F104 & 4.1 & 1.2 & 1.0 & 0.8 & 0.5 & 1.9 & 3.6 \\
F206 & 2.3 & 0.7 & 1.4 & 0.8 & 0.5 & 1.7 & 0.9 \\
F215 & 2.9 & 2.8 & 0.2 & 0.6 & 0.5 & 1.4 & 3.1 \\
F214 & 3.1 & 1.1 & 2.0 & 0.8 & 0.8 & 1.1 & 4.2 \\
F151 & 3.2 & 2.2 & 0.2 & 0.8 & 1.2 & 2.5 & 2.5 \\
F212 & 2.9 & 1.7 & 0.4 & 0.6 & 0.4 & 2.9 & 1.2 \\
F324 & 0.9 & 0.2 & 0.4 & 0.2 & 0.2 & 0.8 & 0.2 \\
F207 & 2.0 & 1.1 & 2.2 & 0.6 & 0.7 & 2.3 & 2.3 \\
F213 & 1.2 & 0.5 & 0.8 & 1.2 & 0.4 & 0.8 & 0.7 \\
F109 & 5.5 & 2.0 & 1.6 & 0.8 & 1.6 & 4.0 & 4.0 \\
F211 & 1.1 & 0.4 & 0.6 & 0.8 & 0.3 & 0.7 & 0.7 \\
F219 & 0.6 & 0.4 & 0.6 & 0.2 & 0.6 & 0.9 & 0.9 \\
F323 & 0.7 & 0.3 & 0.6 & 0.2 & 0.2 & 0.2 & 0.2 \\
F401 & 0.3 & 0.1 & 0.2 & 0.2 & 0.1 & 0.1 & 0.1 \\
\hline
\end{tabular}


relationship between the carbonate content and soluble salt concentration. The effect of shaking time on the ion concentrations of water extract was examined for selected soil samples. The results indicated that there is no significant effect of shaking tame on the ionic concentrations in the extract.

Fig. 1 shows the measured $\mathrm{pH}$ values for two soil samples (F219 and K1) as a function of standing time after shaking. For the F109 soil, the $\mathrm{pH}$ values measured at SWR of 1:2.5 and 1:5 were plotted against standing time after shaking for $1 \mathrm{~h}$. For the $\mathrm{K} 1$ soil the $\mathrm{pH}$ values measured at the same SWR of 1:5 but after different shaking time of 0.5 and $1 \mathrm{~h}$ were plotted. The $\mathrm{pH}$ for the F109 soil gradually increased as the standing time increased up to about 8.1 at a standing time of $264 \mathrm{~h}$ and then decreased to about 6.8 after about $600 \mathrm{~h}$. The two plots for the SWR of 1:5 and 1:2.5 almost coincided, suggesting that the SWR does not affect the soil pH. As seen from the congested data points at short standing times, the $\mathrm{pH}$ was almost constant within $2 \mathrm{~h}$ after shaking. For the K1 soil,

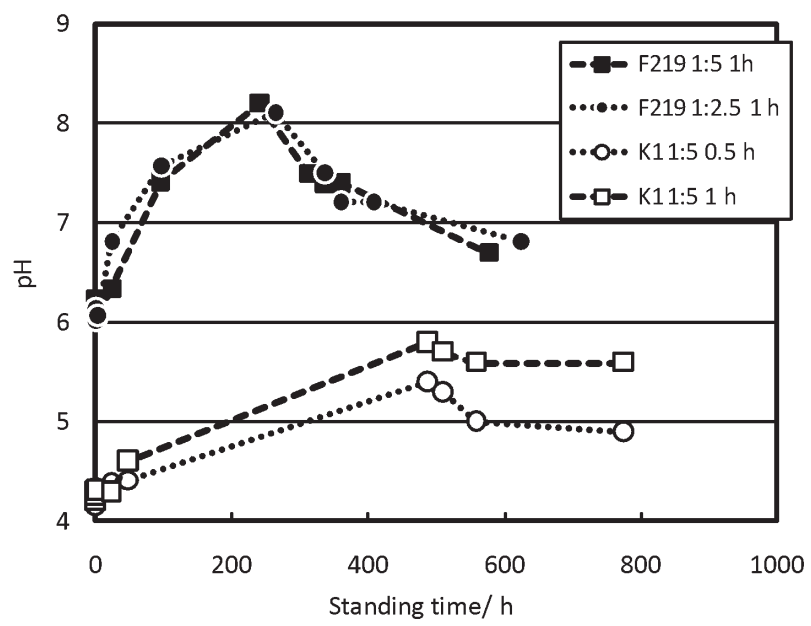

Fig. 1. The effect of soil to water ratio and standing time on the measured $\mathrm{pH}$ for tow soil samples. the trend of the $\mathrm{pH}$ change was basically similar, i. e., the $\mathrm{pH}$ gradually increased as standing time increased and then decreased again. But the increment in $\mathrm{pH}$ was not as large as 1 unit. For this soil sample, the $\mathrm{pH}$ was almost constant within $24 \mathrm{~h}$ after shaking and the shaking time did not virtually affect the $\mathrm{pH}$ at least in a short period after shaking. The data for other greenhouse soils behaved in quite a similar way in that they all showed $\mathrm{pH}$ maxima at 250-300 $\mathrm{h}$ after shaking (Fig. 2).

These observations are basically in accordance with those in the preceding studies in that the SWR does not affect pH measurement (Davis, 1943; Committee for Soil Testing, 2000). In addition, the fairly large $\mathrm{pH}$ change after prolonged standing time explains why relatively short standing times are recommended for soil pH measurement in the existing standards (Soil Environmental Analysis Committee, 1977; Committee for Soil Testing, 2000; ISO, 2005). Being reproducible and taking short time are important for routine analytical method for soil testing. However, whether obtained values are chemically meaningful or not is other thing. Table 1 shows that the $\mathrm{pH}$ values obtained in $2 \mathrm{~h}$ after shaking ranged from 6.8 to 7.2 for soils containing significant amount of carbonate (Fig. 2 and Table 1) and they are definitely too low. Thus the conventional method for soil $\mathrm{pH}$ measurement is not suitable to obtain chemically meaningful equilibrium $\mathrm{pH}$ values.

When a soil solution is at equilibrium with pure calcite, the following equation holds;

$$
K_{\mathrm{sp}}=\left(\mathrm{Ca}^{2+}\right)\left(\mathrm{CO}_{3}^{2-}\right)
$$

where $K_{\mathrm{sp}}$ is the solubility product of calcite and the parentheses indicate the thermodynamic activity. The activity of carbonate ion can be related to the activity of hydrogen carbonate ion and carbonic acid through;

$$
K_{\mathrm{a} 1}=\frac{\left(\mathrm{HCO}_{3}^{-}\right)\left(\mathrm{H}^{+}\right)}{\left(\mathrm{H}_{2} \mathrm{CO}_{3}\right)}
$$

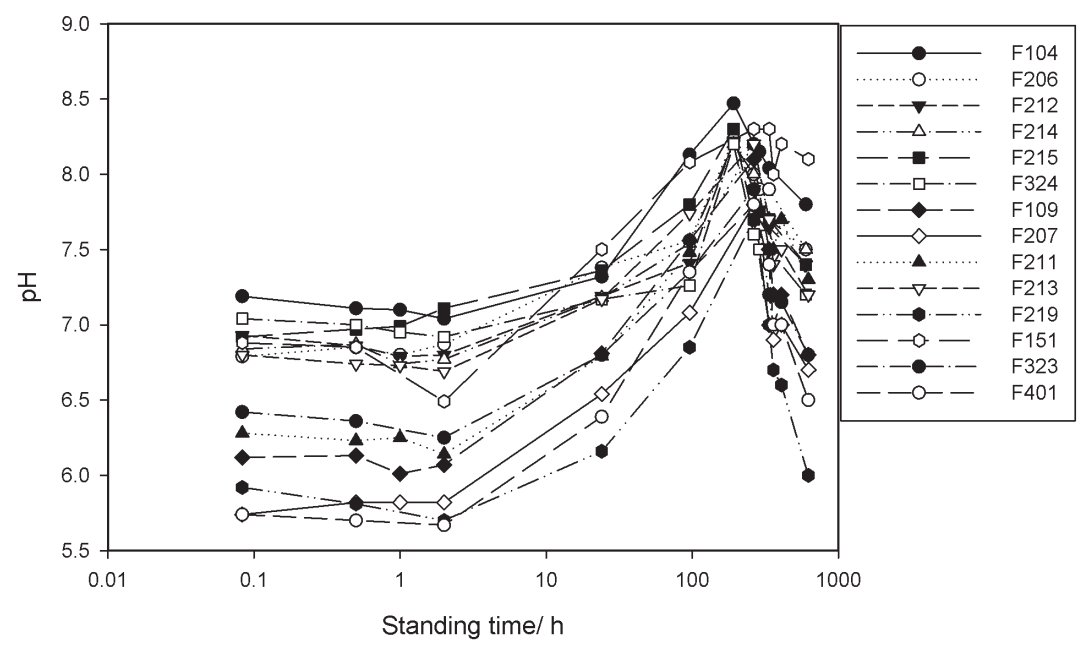

Fig. 2. The soil pH measured at a water to soil ratio of $1: 2.5$ as a function of standing time. Logarithmic scale was used for abscissa to avoid congestion of the plot points. 
and

$$
K_{\mathrm{a} 2}=\frac{\left(\mathrm{CO}_{3}^{2-}\right)\left(\mathrm{H}^{+}\right)}{\left(\mathrm{HCO}_{3}^{-}\right)}
$$

where $K_{\mathrm{a} 1}$ and $K_{\mathrm{a} 2}$ are the first and second dissociation constant of carbonic acid. Since the partial pressure of $\mathrm{CO}_{2}$ in the air is almost constant, the activity of carbonic acid in the soil solution can be related to the atmospheric partial pressure of $\mathrm{CO}_{2}$ through;

$$
\left(\mathrm{H}_{2} \mathrm{CO}_{3}\right)=K_{\mathrm{H}} P_{\mathrm{CO} 2}
$$

where $\left.K_{\mathrm{H}}(\mathrm{mol} \mathrm{atm})^{-1}\right)$ and $P_{\mathrm{CO} 2}(\mathrm{~atm})$ are the Henry constant and the partial pressure of $\mathrm{CO}_{2}$. By combining eqs. (2), (3) and (4), the activity of carbonate ion can be related to the partial pressure of $\mathrm{CO}_{2}$ in the air;

$$
\left(\mathrm{CO}_{3}{ }^{2-}\right)=\frac{K_{\mathrm{al}} K_{\mathrm{a} 2} K_{\mathrm{H}} P_{\mathrm{CO} 2}}{\left(\mathrm{H}^{+}\right)^{2}}
$$

By substituting eq. (5) into eq. (1) and taking common logarithm of the both side, following equation is obtained.

$$
\begin{aligned}
\mathrm{pH}= & -\frac{1}{2}\left(\log K_{\mathrm{a} 1}+\log K_{\mathrm{a} 2}+\log K_{\mathrm{H}}+\log P_{\mathrm{C} 02}\right. \\
& \left.+\log \left(\mathrm{Ca}^{2+}\right)-\log K_{\mathrm{sp}}\right)
\end{aligned}
$$

In the derivation the negative logarithm of proton activity was set equal to $\mathrm{pH}$. Since $\log K_{\mathrm{a} 1}=-6.35, \log K_{\mathrm{a} 2}=10.33$, $\log K_{\mathrm{H}}=-1.46$, and $\log K_{\mathrm{sp}}=-8.35$ (Novozamsky and Beek, 1976), eq. (6) reduces to;

$$
\mathrm{pH}=4.89-\frac{1}{2}\left(\log P_{\mathrm{CO} 2}+\log \left(\mathrm{Ca}^{2+}\right)\right)
$$

This means that the $\mathrm{pH}$ of a soil solution at equilibrium with calcite is solely determined by the $\mathrm{Ca}^{2^{+}}$activity and the partial pressure of $\mathrm{CO}_{2}$ in which the $\mathrm{pH}$ measurement is carried out. In this experiment the partial pressure of $\mathrm{CO}_{2}$ in the room was on average $0.00035 \mathrm{~atm}$. Eq. (7) further reduces to;

$$
\mathrm{pH}=6.62-\frac{1}{2} \log \left(\mathrm{Ca}^{2^{+}}\right)
$$

As shown in Table 1, all the soil samples contained free carbonate and the equilibrium $\mathrm{pH}$ of the soil solutions at equilibrium with them can be estimated with eq. (8). Since the soil pH plotted in Fig. 2 was measured at a SWR of 1:2.5, the values of the $\mathrm{Ca}^{2^{+}}$activity at that SWR are needed to use eq. (1). The major ion concentrations at a SWR of 1:2.5 were estimated from the data shown in Table 2 following the method proposed by Wada et al. (2006-a, 2006-b). In this calculation sulfate concentration was estimated in a way similar to those for chloride and nitrate. The activity of $\mathrm{Ca}^{2+}$ was then calculated with a computer code PHREEQC (Parkhurst and Appelo, 1999) and the equilibrium $\mathrm{pH}$ was estimated with eq. (8). The $\mathrm{pH}$ measured after $2 \mathrm{~h}$ standing was plotted against theoretical pH in Fig. 3. In the same figure, the observed maximum $\mathrm{pH}$ was also plotted against the theoretical $\mathrm{pH}$ for comparison.

Apparently, the $\mathrm{pH}$ values after $2 \mathrm{~h}$ standing were lower than the theoretical values by 0.7 to $3 \mathrm{pH}$ units. The difference between the observed and theoretical values were relatively small for soils containing $>10 \mathrm{cmol}$ $\mathrm{kg}^{-1}$ carbonate than for those with carbonate content $<$

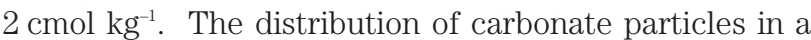
soil sample may not have been uniform and the whole soil may not have been at equilibrium with calcite. If the calcite content in the soil sample is low, it may dissolve during shaking and standing. However, in view of very low solubility of calcite, complete dissolution of $>10 \mathrm{cmol} \mathrm{kg}^{-1}$ of calcite is not probable. The large downward deviation of the plot points (open circle) for high carbonate content soils strongly suggests that the $1 \mathrm{~h}$ shaking and $2 \mathrm{~h}$

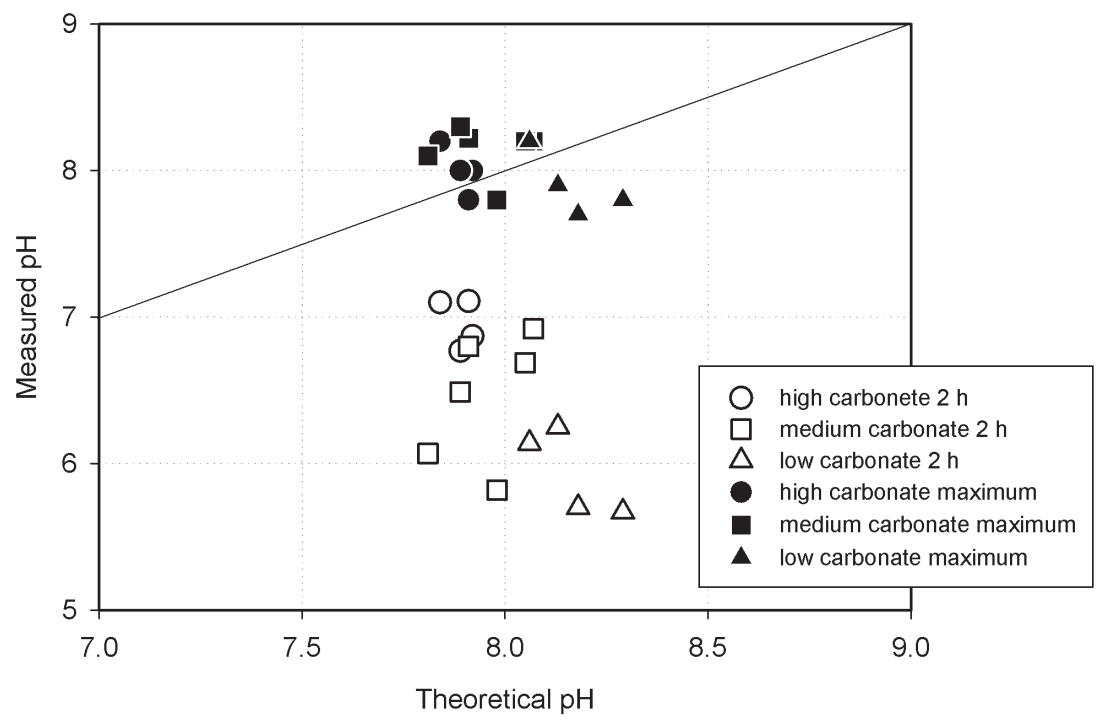

Fig. 3. The relationship between the measured $\mathrm{pH}$ and theoretically predicted $\mathrm{pH}$. The open symbols refer to measured pHs after $2 \mathrm{~h}$ standing and closed ones maximum pHs attained after $192-264 \mathrm{~h}$ standing. 
standing is not enough for equilibration.

Fig. 3 also shows the plots for highest $\mathrm{pH}$ values (closed symbols), which were obtained after 192 to $264 \mathrm{~h}$ of standing. All these plots scatter around 1:1 line, suggesting that the maximum $\mathrm{pH}$ values are close to the theoretical $\mathrm{pH}$ values that were calculated under the assumption of the presence of free carbonate. The deviation from the theoretical value was mostly within $\pm 0.5 \mathrm{pH}$ units. There is little chemical background in regarding the maximum $\mathrm{pH}$ as the equilibrium $\mathrm{pH}$ with respect to carbonate dissolution. However, the fact that all the plot points (closed symbols) fell in the vicinity of the 1:1 line deserves further study.

It is well known that soil $\mathrm{pH}$ increases as oxidationreduction potential decreases. In the present study, all the centrifuge tubes used for $\mathrm{pH}$ measurement were kept open to allow free access of the air and it is unlikely that reducing condition prevailed in all of them, although soil color turned grayish in some tubes. If it had occurred to some extent, it would have not affected the suspension $\mathrm{pH}$, because the $\mathrm{pH}$ is solely determined under the presence of calcite by the $\mathrm{Ca}^{2+}$ activity and equilibrium $\mathrm{CO}_{2}$ pressure (eq. (8)) irrespective of oxidation-reduction condition. During standing after shaking, some of the water evaporated from the suspensions, resulted in lower SWR. However, this would not have affected the $\mathrm{pH}$ because, as shown in Fig. 1, the SWR has little effect on $\mathrm{pH}$.

The acidic K1 soil showed gradual but significant $\mathrm{pH}$ increase during prolonged standing (Fig. 1). This suggests that the increase in $\mathrm{pH}$ is not necessarily a result of slow carbonate equilibration.

The results of the present study strongly suggest that the conventional methods for soil pH measurement, i. e., shaking for $<1 \mathrm{~h}$ and standing for $<3 \mathrm{~h}$, is not adequate to obtain equilibrium $\mathrm{pH}$ values for greenhouse soils containing free carbonates. During prolonged standing after shaking, the $\mathrm{pH}$ gradually rose and theoretically reasonable values were attained after 192 to $264 \mathrm{~h}$ and then dropped. Even if the attained maximum $\mathrm{pH}$ values represent the equilibrium with regard to carbonate dissolution, it is not convenient to wait for more than 8 days for $\mathrm{pH}$ measurement. Further studies are needed to improve the method to obtain equilibrium $\mathrm{pH}$ values quickly and to understand the mechanism of up and down in $\mathrm{pH}$ during prolonged standing.

\section{ACKNOWLEDGEMENTS}

This study was supported in part by a Grant-in-Aid for Scientific Research from the Japanese Society for Promoting Sciences (\# 21380048).

\section{REFERENCES}

Committee on Soil Testing 2000 Soil Testing-Methods and Comments-, Japanese Society of Geotechnical Engineering, Tokyo (Japan), pp. 159-165 (in Japanese)

Davis, L. E. 1943 Measurements of $\mathrm{pH}$ with the glass electrode as affected by soil moisture. Soil Sci., 56: 405-422

ISO 2005 Determination of pH. ISO 10390, Soil Quality

Novozamsky, I. and J. Beek 1976 Common solubility equilibria in soils. In "Soil Chemistry. A. Basic Elements", eds. G. H. Bolt and M. G. M. Brugenwert, Elsevier, Amsterdam, pp. 96-125

Okajima, H. 1981 Soil solution composition and land use. In "Adsorption Phenomena in Soils", ed. by Japanese Society of Soil Science and Plant Nutrition, Hakuyu-sha, Tokyo, pp. 85-128 (in Japanese)

Parkhurst, D. L. and C. A. J. Appelo 1999 User's Guide to PHREEQC (Version 2) - A comuputer program for speciation, batchreaction, one dimensional transport and inverse geochmical calculations. U. S. Geol. Surv. Water Resour. Inv. Rep., 99-4259, pp. 312

Soil Environmental Analysis Methods Committee 1997 Methods of Soil Environmental Analysis, Hakuyu-sha, Tokyo, pp. 427 (in Japanese)

Thomas, G. W. 1996 Soil pH and soil acidity. In "Methos of Soil Analysis. Part 3. Chemical Methods", ed. by D. L. Sparks, Soil Sci. Soc. Amer. Inc., Madison, pp. 475-490

Wada, S. -I. 1997 Rapid and sensitive method for on-site estimation of small amount of carbonate in soils. Soil Sci. Plant Nutr., 43: 45-50

Wada, S. -I., K. Odahara, N. Gunjikake and S. Takada 2006-a Prediction of nitrate and chloride ion concentrations in soil solution using water extracts. Soil Sci. Plant Nutr., 52: 1-4

Wada, S. -I., K. Odahara, N. Gunjikake and S. Takada 2006-b Empirical equations for prediction of major ion concentrations in soil solutions using concentrations in water extracts.. Soil Sci. Plant Nutr., 52: 257-263 